\title{
Síndrome otodental y su manejo en la estomatología pediátrica. Una revisión narrativa
}

\section{Otodental syndrome and its management in pediatric stomatology. A narrative review}

\author{
Anabel Collado-Gabino y Violeta Magaña-Barrios² \\ ${ }_{1}^{1}$ Alumna de la Especialización en Estomatología del Niño y del Adolescente, Facultad de Estudios Superiores \\ Zaragoza, UNAM \\ ${ }^{2}$ Profesora adscrita al Servicio de Estomatología Pediátrica del Hospital Infantil de México Federico Gómez
}

\section{ResUMEN}

Introducción. El síndrome otodental se caracteriza por pérdida auditiva neurosensorial y la presencia de dientes bulbosos agrandados (globodoncia) que afectan a la dentición primaria y permanente. Objetivo. Presentar el estado del arte del conocimiento sobre las características clínicas del síndrome otodental en el niño y en el adolescente. DesarroIlo. Se encontró como cuadro clínico principal globodoncia, pérdida auditiva de baja frecuencia, con aparición variable durante la vida del paciente; así como el retardo en la erupción en la dentición temporal y permanente. Además, se observa que estas manifestaciones pueden presentarse en uno o en varios integrantes de la familia y estar asociadas a otras manifestaciones faciales y oculares. Conclusión. Existe poca información reciente sobre la frecuencia de esta condición en el mundo, tomando en cuenta que la mayoría de los casos se limita a la ascendencia europea u oriental, coincidiendo en el cuadro clínico característico. Por lo anterior, se sugiere considerar este diagnóstico clínico cuando se detecten algunas alteraciones dentales raras como la globodoncia, para un tratamiento integral sistémico incluyendo el de estomatología pediátrica.

Palabras clave: Síndrome otodental, globodoncia, displasia otodental, anomalías dentarias, otodentodisplasia familiar.

\section{Abstract}

Introduction. Otodental syndrome is characterized by sensorineural hearing loss and the presence of enlarged bulbous teeth (globodontia) that affect primary and permanent dentition. Objective. To present the state of the art of knowledge on the clinical characteristics of otodental syndrome in children and adolescents. Development. The main clinical picture was globodontia, low frequency hearing loss, with variable appearance during the patient's life, as well as the delay in the eruption of primary and permanent dentition. In addition, it is observed that these manifestations can occur in one or more members of the family and be associated with other facial and ocular manifestations. Conclusion. There is little recent information on the frequency of this condition in the world, considering that most cases are limited to European or Eastern descent, coinciding with the characteristic clinical picture. Therefore, it is suggested to consider this clinical diagnosis when some rare dental alterations such as globodontia are detected for a comprehensive systemic treatment including pediatric stomatology.

Keywords: Otodental syndrome, globoodontics, otodental dysplasia, abnormalities of tooth, family otodentodysplasia. 


\section{INTRODUCCIÓN}

El síndrome otodental es una enfermedad rara también conocida como otodentodisplasia familiar o displasia otodental. En el catálogo en línea de genes humanos y trastornos genéticos (OMIM), tiene el registro 166750. Es una enfermedad hereditaria y de tipo autosómica dominante, caracterizada por alteraciones en la morfología dental, así como pérdida auditiva neurosensorial de alta frecuencia; asociada también a anomalías oculares. ${ }^{1-7}$ Las manifestaciones dentales del síndrome consisten en molares grandes en forma de globo (globodoncia); los cuales por su anatomía irregular tienen gran predisposición a caries dental. Además, se identifican premolares ausentes o microdónticos y retraso en la erupción de los dientes afectados.

El síndrome otodental es causado por microdeleción homocigota que afecta al gen FGF3, en el cromosoma 11q13.3, se sugiere que la pleiotropía de este síndrome se debe a un defecto genético en el neuroectodermo. ${ }^{1-4}$ Es un síndrome con expresividad variable, alta penetrancia y demuestra una expresividad variable con algunos pacientes que solo experimentan pérdida de la audición y otros presentan alteraciones dentales marcadas sin pérdida auditiva. Su expectativa de vida es similar a un paciente sano. ${ }^{2}$

El primer caso de síndrome otodental fue descrito en 1969 en Hungría, en una madre y su hijo y en 1975, se consideró que algunos pacientes pueden tener baja estatura. ${ }^{3,4,6}$

Su epidemiología aún no está determinada, al menos nueve familias se han descrito en la literatura. ${ }^{2}$ El fenotipo se ha reportado en casos simples y hasta ahora, un paciente británico, una niña de origen irlandés, una familia de Brasil, un niño chino, una familia de origen polaco, una familia austriaca, una familia de italiana (seguida a lo largo de seis generaciones) y una familia belga, se ha descrito en la literatura.

En este contexto el propósito de esta revisión es presentar el estado del arte del conocimiento sobre las características clínicas del síndrome otodental en el niño y en el adolescente, para que los estudiantes y odontopediatras tengan el conocimiento de este síndrome raro y lo puedan diagnosticar.

\section{Epidemiología}

Los artículos sobre el síndrome otodental son escasos y el más reciente es del año 2016. Los casos reportados son originarios de Alemania, Bélgica, España, China, Corea del Sur, Turquía, Estados Unidos y Brasil, percibiendo que la mayoría de los casos son de descendencia europea o asiática. Las edades de los pacientes son entre uno y 13 años. Cabe mencionar que, en la mayoría de los estudios, se llevó un seguimiento del paciente de por lo menos un año.

Por tanto, el portal de información de enfermedades raras reporta una prevalencia de casos de $<1 / 1,000,000$ casos. $^{6}$

\section{Características clínicas}

Los pacientes presentan pérdida auditiva neurosensorial bilateral progresiva, por encima de $1000 \mathrm{~Hz}$ que puede comenzar en la infancia o a mediana edad. Es obligatorio un seguimiento periódico de la audición, así como, en caso de ser necesario, el uso de audífonos. La hipoacusia es progresiva y bilateral; comenzando en la infancia y progresando hasta una media aproximadamente a los 35 años. ${ }^{2-9}$

Otra característica asociada a este síndrome son las anomalías oculares; tales como: coloboma coriorretiniano y del iris, así como, ocasionalmente, microcórnea, microftalmia, opacidad lenticular, coloboma del cristalino y atrofia del epitelio pigmentario del iris. ${ }^{6}$

Dentro de sus manifestaciones estomatológicas se identifican características de tipo craneofacial y bucales. Se han reportado algunos rasgos faciales dismórficos como cara alargada, fosas nasales antevertidas, un surco nasolabial largo y una apariencia de mejillas voluminosas (Figura 1). ${ }^{2-15}$ 

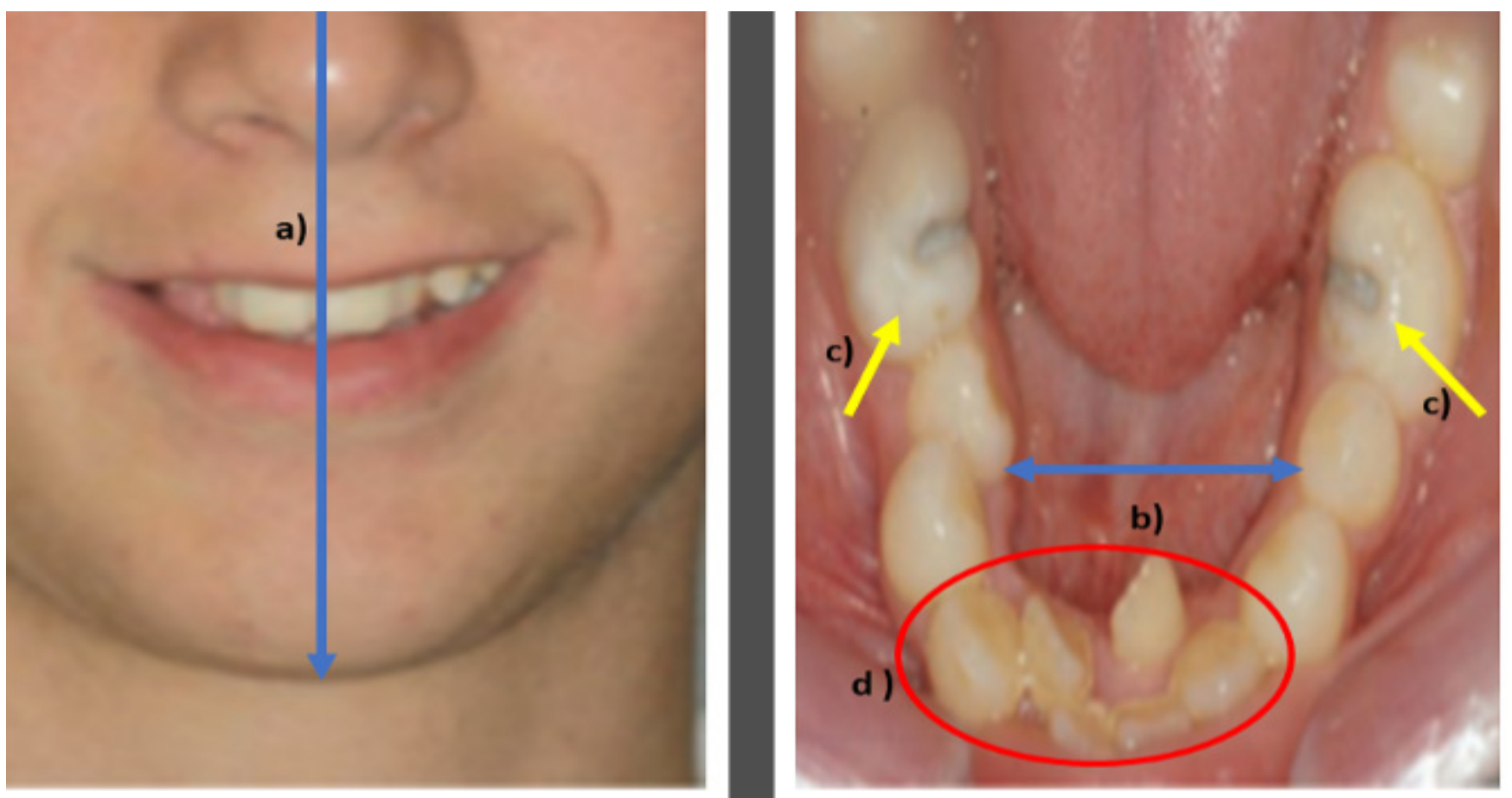

Figura 1. Paciente con síndrome Otodental; a la izquierda un paciente con biotipo facial dolicofacial, característico del síndrome; a la derecha b) arcada estrecha c) molares inferiores con globodoncia, y d) apiñamiento (Modificado de Gómez et al., 2004)

Entre las manifestaciones bucales identificamos que la dentición primaria está más afectada, ya que hay coronas bulbosas de caninos, premolares: Dentición primaria más gravemente afectada; grandes coronas bulbosas de caninos, premolares y molares (globodoncia); posible fusión de dientes molares-premolares; dientes macrodónticos, aparentemente formados por la fusión de dientes malformados más pequeños; ausencia parcial o total de premolares; todos los incisivos tienen morfología normal; dientes supernumerarios conoides; manchas hipoplásicas amarillas en el esmalte de caninos y molares; fisuras verticales en esmalte; taurodontismo; cámaras de pulpa septadas en molares; raíces cortas; piedras de pulpa; odontomas y erupción retardada. (Figuras 2). ${ }^{2-15}$

La globodoncia es una hiperplasia del esmalte con desaparición de las cúspides y abultamiento de los rebordes marginales en los dientes posteriores (principalmente en el primer y segundo molar) y en los dientes anteriores puede presentarse un aumento de los cíngulos; dando un aspecto globular o en hoja de trébol. Se ha señalado que no se afectan los incisivos (Figura 3). ${ }^{4}$

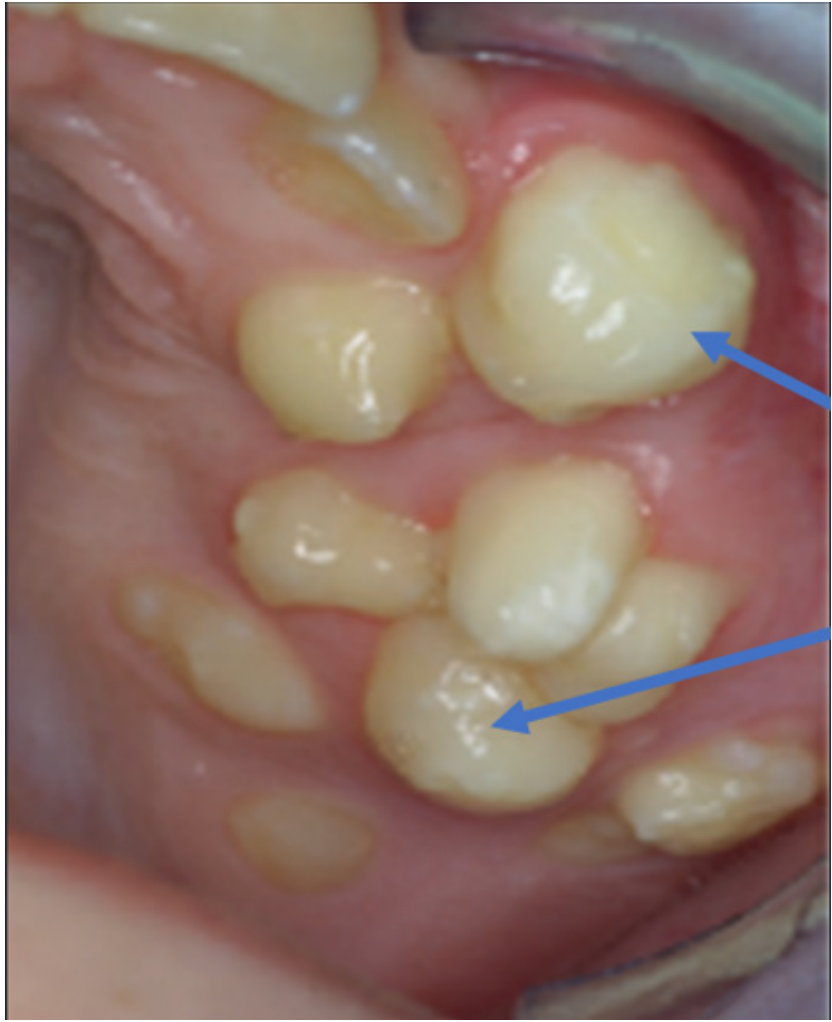

Figura 2. En el síndrome otodental se ven afectados principalmente los molares, aunque también pueden estar comprometidos los premolares y caninos. Las flechas de la imagen muestran a los molares superiores con globodoncia y apiñamiento (Modificado de Bloch-Zupan et al., 2012) ${ }^{2}$ 

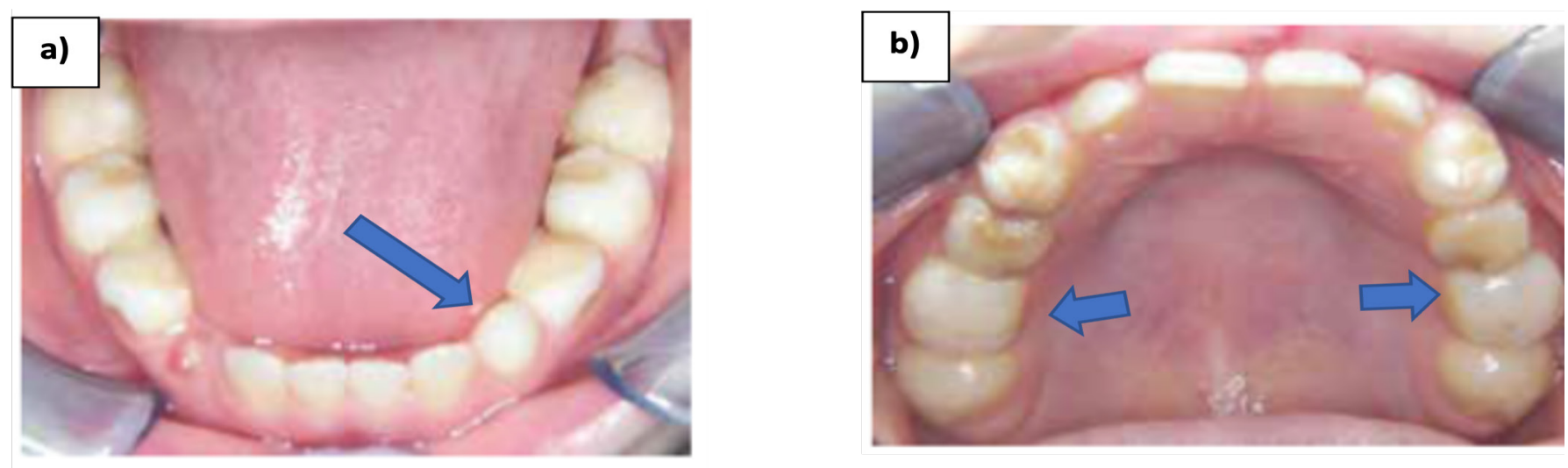

Figura 3. Globodoncia a) en la arcada inferior los molares inferiores presentan globodoncia, los caninos no han sido afectados (flecha; b) en la arcada superior tanto caninos como molares presentan globodoncia; sin embargo, estos últimos han sido rehabilitados con coronoplastías (flechas) (Modificado de Enright et al., 2015) ${ }^{21}$

Existen pocas alteraciones en los cortes histológicos realizados en los órganos dentarios afectados. Un corte en el tercio apical muestra tres conductos radiculares conectados con una cámara pulpar grande a nivel coronal y en una sección sagital no se observan alteraciones en los tejidos dentarios, tan sólo un pequeño estrechamiento del grosor del esmalte, mientras que en la sección bucal se observa como un intento de formar una cúspide accesoria. En cuanto al tejido duro solo se observan alteraciones en las manchas blanco-amarillentas como varillas del esmalte de esta zona son prominentes, las líneas incrementales son irregulares, y el área intervarillar contiene espacios vacíos similares a los defectos de los dientes con esmalte hipomaduro. En la línea amelo-dentinaria se observan unas áreas de crecimiento en dirección a la superficie del diente, y la dentina subyacente presenta túbulos dentinarios irregulares y escasos. ${ }^{3,5-11}$

En las radiografías intraorales y en la ortopantomografía se observa una forma dentaria aumentada con aumento del tamaño mesio-distal de caninos, premolares y molares, así como del tamaño de sus cámaras pulpares, apreciándose taurodontismo y retraso en el cierre apical de segundos premolares y molares (Figura 4). 3,7-9 Se puede observar cámaras pulpares duplicadas con dentículo formación divididas por un tabique dental longitudinal.

Existe poca información reciente sobre la frecuencia y caracterización de esta condición en el mundo, tomando en cuenta que la mayoría de los casos se limita a la ascendencia europea u oriental. Además, en la literatura clínica poco se resalta el abordaje estomatológico de estos pacientes, por lo que es necesario integrar las características clínicas sistémicas y estomatológicas que permitan identificar el síndrome otodental en el niño y en el adolescente para un tratamiento integral (Cuadro 1).

En los estudios realizados, se encontró que el cuadro clínico de mayor frecuencia es la presencia de la globodoncia, taurodontismo, retraso de la erupción y la pérdida auditiva; sin embargo, la pérdida auditiva en el estudio del árbol genealógico es muy variable entre cada integrante, ya que algunos presentaban las anormalidades dentarias con o sin pérdida auditiva, recordando que este signo clínico puede manifestarse en cualquier etapa de la vida. También se encuentra otras anomalías dentarias de número, estructura, forma y tamaño; por ejemplo, agenesia de premolares, dientes supernumerarios, presencia de manchas amarillo-blanquecinas, esmalte inmaduro, cámaras pulpares dobles, microdoncia o macrodoncia por fusión dentaria. Todas las alteraciones dentales afectan a ambas denticiones, principalmente molares, premolares y caninos. Esta irregularidad puede provocar apiñamiento dental. La asimetría facial es una manifestación extraoral frecuente de este síndrome, así como un biotipo facial dolicofacial. Los signos menos frecuentes son el coloboma, alteraciones de la retina, ptosis del ojo izquierdo, microtia, deformidad auricular o microcefalia. 


\section{Cuadro 1. Estudios de pacientes con síndrome otodental}

\begin{tabular}{|c|c|c|c|}
\hline $\begin{array}{c}\text { Autor/ } \\
\text { Año }\end{array}$ & País & $\begin{array}{c}\text { Sujetos de } \\
\text { estudio }\end{array}$ & Hallazgos \\
\hline
\end{tabular}

\begin{tabular}{|c|c|c|}
\hline $\begin{array}{l}\text { Witkop et } \\
\text { al. }(1976)^{24}\end{array}$ & Alemania & Familia polaca \\
\hline
\end{tabular}

Los audiogramas de esta familia mostraron umbrales auditivos bajos en el padre y un hijo con globodoncia y en otros familiares sin el defecto dental. El otro hijo con dientes anormales tenía un audiograma de apariencia normal. La ausencia de dientes premolares y manchas amarillo-blanquecinas de hipomaduración local del esmalte en los caninos también fueron hallazgos en esta familia.

Chen et al. China $(1988)^{3}$

Van

Doorne et

all. $(1998)^{16}$
Bélgica

Niño de 13 años

Seguimiento de un niño chino de 3 años

La audición era normal. Las anomalías dentales consistieron en la erupción tardía de los molares con forma de globo, los caninos deciduos bulbosos y las cámaras pulpares dobles en los molares. Las radiografías tomadas 4 años después mostraron molares taurodónticos, dientes microdónticos supernumerarios, formación retardada de premolares y probable aplasia de los segundos premolares mandibulares.

Las anomalías de la dentición decidua y permanente incluyeron caninos bulbosos, dientes posteriores en forma de globo y agenesia de premolares maxilares. Se demostró la pérdida auditiva neurosensorial de alta frecuencia, y los resultados de genética indicaron un rasgo autosómico dominante. Este paciente presentó hallazgos no reportados previamente, incluyendo macrodoncia generalizada, mineralización retardada de los premolares mandibulares, y caninos maxilares permanentes.

Innis et al. Estados Unidos Familia $(1998)^{15}$

Sedano et Estados Unidos al. $(2001)^{1}$

Niña de 5 años

Sus incisivos maxilares y mandibulares estaban dentro de los límites normales. Las áreas premolares/molares en todos los cuadrantes estaban ocupadas por dientes macrodónticos que mostraban forma globular, los caninos tenían una forma redondeada similar. Áreas de esmalte hipoplásico amarillo. Las radiografías revelaron que algunos de los dientes anormales tenían cámaras de pulpa bifurcadas y piedras o cálculos pulpares. Los gérmenes dentales de los premolares estaban ausentes. La audiometría demostró que el niño tenía una pérdida auditiva neurosensorial bilateral marcada para frecuencias superiores a $1000 \mathrm{~Hz}$. 


\section{Cuadro 1. Estudios de pacientes con síndrome otodental}

\begin{tabular}{|c|c|c|c|}
\hline $\begin{array}{c}\text { Autor/ } \\
\text { Año }\end{array}$ & País & $\begin{array}{c}\text { Sujetos de } \\
\text { estudio }\end{array}$ & Hallazgos \\
\hline $\begin{array}{l}\text { Gómez et } \\
\text { al. }(2004)^{8}\end{array}$ & España & $\begin{array}{l}\text { Paciente varón } \\
\text { de } 13 \text { años }\end{array}$ & $\begin{array}{l}\text { Asimetría facial, en la exploración intraoral los } \\
\text { dientes desde caninos a molares presentan globo- } \\
\text { doncia marcada a nivel de segundos premolares } \\
\text { y molares, con ausencia total de cúspides, clase } \\
\text { II molar y apiñamiento dental. Antecedentes de } \\
\text { soplo cardíaco y con antecedentes familiares } \\
\text { de globodoncia. Como tratamiento se realizaron } \\
\text { extracciones para aliviar apiñamiento y corono- } \\
\text { plastías. }\end{array}$ \\
\hline
\end{tabular}

Colter et Estados Unidos al. $(2005)^{20}$
Niño de 9 años

Niña de 10 años

Silva et al. Brasil $(2006)^{25}$
Gregory- Bélgica

Evans et al.

$(2007)^{4}$
Tres familias

Niña de 8 años con pérdida auditiva
Anodoncia del premolar superior izquierdo, retraso de la erupción, coronas bulbosas en caninos y molares de ambas denticiones, fisuras de esmalte verticales profundas que separan las cúspides de los molares afectados, y áreas amarillas hipoplásicas en las superficies labiales de los caninos. Radiográficamente se observan molares anormales posiblemente son el producto de la fusión de las cúspides. Las cámaras de pulpa parecían estar duplicadas, y posiblemente un diente supernumerario u odontoma complejo está presente. Sin pérdida de la audición.

Se identificó pérdida auditiva gradual retraso en la erupción dental de la dentición temporal y permanente. También se identificó rinitis alérgica y datos de respiración bucal con cambios posturales como anteriorización de la cabeza con rectificación de la columna cervical e hiperlordosis abdominal con anteversión pélvica; presencia de hábitos parafuncionales como onicofagia. Fisionomía inexpresiva, cara alargada, anteversión de las narinas, filtrum largo, labio superior hipotónico, mejillas flácidas e hiperactividad del músculo mentoniano al cierre labial.

Se realizó una exploración en todo el genoma y las tres familias resultaron afectadas con el síndrome de Oto-dental tenían el fenotipo único de dientes molares gravemente agrandados (globodoncia) y una perrdida auditiva neurosensorial de alta frecuencia. Además, se identificó coloboma ocular segregado con síndrome oculo - oto-dental.

No se observó displasia dental, excepto la falta de incisivos, premolares y no hubo afectación ocular. La paciente tenía pérdida auditiva neurosensorial bilateral. Se observó un paladar profundo y estrecho, y fue la única anomalía reportada en un caso de síndrome otodental. Un primo hermano presenta pérdida auditiva y otro primo con pérdida auditiva y labio hendido. 


\section{Cuadro 1. Estudios de pacientes con síndrome otodental}

\begin{tabular}{|c|c|c|c|}
\hline $\begin{array}{c}\text { Autor/ } \\
\text { Año }\end{array}$ & País & $\begin{array}{c}\text { Sujetos de } \\
\text { estudio }\end{array}$ & Hallazgos \\
\hline $\begin{array}{l}\text { Cehreli et } \\
\text { al. }(2014)^{26}\end{array}$ & Turquía & Niña de 6 años & $\begin{array}{l}\text { Retraso en la erupción de los caninos temporales, } \\
\text { globodoncia y pérdida auditiva asociada. }\end{array}$ \\
\hline $\begin{array}{l}\text { Enright et } \\
\text { al. }(2015)^{21}\end{array}$ & & Niña de 8 años & $\begin{array}{l}\text { Se detectó pérdida auditiva en la infancia y } \\
\text { posteriormente se utilizaron audífonos, sin retraso } \\
\text { en el lenguaje y la comprensión relacionados } \\
\text { con la discapacidad auditiva. Caninos primarios } \\
\text { inferiores y permanentes con coronas bulbosas, } \\
\text { lisas; caninos primarios superiores agrandados y } \\
\text { primeros molares permanentes más pequeños de } \\
\text { lo habitual. }\end{array}$ \\
\hline $\begin{array}{l}\text { Kim et al. } \\
(2016)^{5}\end{array}$ & Corea & Niña de 1 año & $\begin{array}{l}\text { Características dismórficas como ptosis del ojo } \\
\text { izquierdo, deformidad auricular derecha, micro- } \\
\text { cefalia, paladar profundo y línea simio en la mano } \\
\text { derecha. Presentaba microtia derecha con partes } \\
\text { superiores acortadas de las aurículas. Sin embargo, } \\
\text { los resultados del examen otoscópico fue normal. } \\
\text { En el estudio genético se encontró deleción en el } \\
\text { cromosoma 11q13. 2-q13. }\end{array}$ \\
\hline $\begin{array}{l}\text { Su et al. } \\
(2019)^{12}\end{array}$ & China & $\begin{array}{l}\text { Niño chino de } \\
3 \text { años }\end{array}$ & $\begin{array}{l}\text { Se identificó erupción tardía de caninos y molares } \\
\text { primarios. El seguimiento de tres años mostró ca- } \\
\text { ninos y molares primarios bulbosos recientemente } \\
\text { erupcionados con mancha hipoplásica de esmal- } \\
\text { te e hipoacusia neurosensorial a los } 4 \text { años y me-- } \\
\text { dio de edad. Diagnosticamos síndrome otodental } \\
\text { en la madre del paciente con hipoacusia a los } 16 \\
\text { años. La secuenciación de genes y el análisis de } \\
\text { los genes relacionados con la sordera no revela- } \\
\text { ron ninguna mutación o SNP en el paciente y su } \\
\text { madre. }\end{array}$ \\
\hline
\end{tabular}




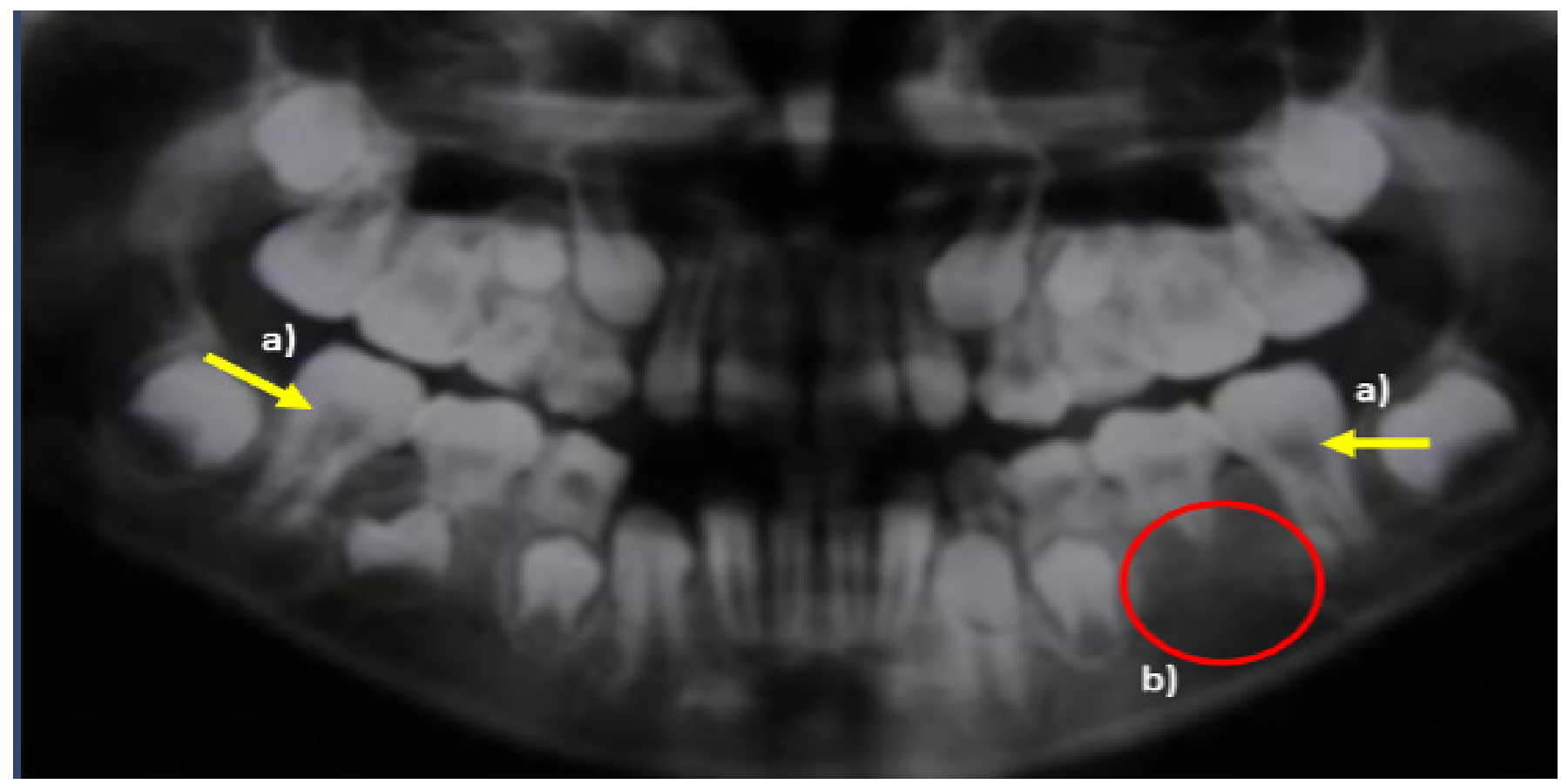

Figura 4. Radiografía panorámica donde se identifica a) taurodoncia en los molares y b) ausencia del germen dentario 35 (Modificado de Enright et al., 2015) ${ }^{21}$

En casos particulares se reporta la anteversión de las narinas, filtrum largo, labio superior hipotónico, mejillas flácidas e hiperactividad del músculo mentoniano al cierre labial y probable respiración bucal. El diagnóstico se determina a través de las características clínicas y el estudio genómico del paciente..$^{5-11}$ Los estudios genéticos identificaron el rasgo autosómico dominante y deleción en el cromosoma 11 q 13. 2-q 13.

\section{Manejo estomatológico en el niño y el ADOLESCENTE}

Por otro lado, la falta de comunicación con el manejo dental de este síndrome es complejo, multidisciplinario y debe incluir un seguimiento regular. Se puede dividir en tratamiento dental preventivo, restaurativo y rehabilitación protésica; además debe llevarse un tratamiento ortopédico-ortodóntico para la intercepción de maloclusiones. ${ }^{2-15}$

Generalmente los padres acuden a consulta por la preocupación de la erupción tardía de los órganos dentarios de sus hijos, por lo cual los pacientes llegan a edades tempranas. Es necesario realizar un buen manejo conductual del paciente considerando la edad, ansiedad dental y la necesidad de una comunicación clara con la entrada visual; si ya se identifica pérdida auditiva sensorial. Se sugiere que el estomatólogo pediatra que atienda por primera vez al paciente, sea él mismo quien realice la atención odontológica subsecuentemente con la finalidad de lograr confianza y seguridad, evitando así, el abandono del tratamiento. ${ }^{16}$

Para el tratamiento estomatológico de estos pacientes, se sugiere seguir las estrategias de comunicación en pacientes con pérdida auditiva y discapacidad ocular.

\section{COMUNICACIÓN ODONTOLÓGICA CON PACIENTES CON PÉRDIDA AUDITIVA}

Se recomienda hablar con voz en tono normal y ligeramente pausada, de frente y dirigiendo la mirada al paciente con lenguaje sencillo y dar oportunidad de aclarar todas las dudas. El odontólogo debe mostrar interés en la situación del paciente con la finalidad de establecer una relación de confianza. ${ }^{17}$ 
También se sugiere la modificación de la técnica "decir, mostrar y hacer" por "mostrar, oler, tocar y hacer", así como establecer señas básicas de comunicación como "abre la boca, cierra, lavar, diente, dolor, tranquila (o), ¿estás bien?"..16-18

\section{COMUNICACIÓN ODONTOLÓGICA CON PACIENTES CON DISCAPACIDAD OCULAR}

Se debe identificar los problemas visuales, así como el uso del sistema braille como medio de comunicación. Las instalaciones deben garantizar el libre acceso al sillón dental, tener buena iluminación. ${ }^{19}$

Es apropiado hablarles de frente y darle la mano para realizar un recorrido para que el niño se sienta seguro y confíe en el profesional de la salud. Los procedimientos deben ser sencillos y cortos, con explicaciones sencillas y refuerzos positivos (se puede permitir la presencia de la madre, de acuerdo con la conducta y la dependencia de la comunicación). Se puede recurrir a técnicas del manejo de la conducta como decir-tocar-probar-oler-hacer, la sensibilización y desensibilización con la finalidad de conocer ruidos, olores e instrumentos. Se puede hacer uso de tipodontos infantiles y permanentes, así como maquetas que puedan tocar los pacientes, lo que facilitará la educación sobre la higiene bucal. ${ }^{19}$

\section{TRATAMIENTO}

El tratamiento de estos pacientes se divide en dos: el tratamiento dental preventivo, que se enfoca a disminuir los factores de riesgo para desarrollar alguna enfermedad bucal, y el tratamiento protésico.

\section{Tratamiento dental PREVENTIVO}

Se aconseja tener una asesoría nutricional, control de biopelícula dental, con técnica de cepillado y aplicaciones de barniz de fluoruro, para prevenir caries y evitar la terapia endodóntica que puede ser difícil por la duplicación de los canales de pulpa en los dientes posteriores afectados. ${ }^{20-22}$
Además, es recomendable la colocación de selladores de fosetas y fisuras, así como el dar un seguimiento clínico y radiográfico de la erupción de los dientes.

\section{TRATAMIENTO RESTAURATIVO Y PROTÉSICO}

Se pueden realizar coronoplastías positivas (incrementos con material compuesto) o coronoplastías negativas (tallado de superficies) que darán una mayor estabilidad oclusal.

En los casos que se requieren múltiples extracciones, se pueden colocar prótesis fijas o removibles. Y se puede considerar la colocación de implantes en la edad adulta. ${ }^{23}$

\section{Conclusiones}

Las anomalías dentales representan características importantes a considerar para el diagnóstico temprano y el tratamiento oportuno de muchos síndromes. La presencia e identificación de los signos más característicos son una herramienta diagnostica a edades tempranas y que es indispensable conocer para los estomatólogos pediatras de primer contacto para la atención odontológica. Además, debemos rescatar la importancia del seguimiento de estos pacientes debido a que parte del cuadro clínico puede desarrollarse en distintas etapas de la vida, como lo es la pérdida auditiva que nos encamina a conocer el manejo odontológico de las distintas discapacidades para garantizar al paciente un trato adecuado y eficiente. Por lo cual, es indispensable la comunicación empática y la elaboración de una historia clínica completa, rescatando siempre, los antecedentes heredofamiliares debido a las características de dominancia y expresividad de este síndrome hereditario.

\section{AgradeCIMIENTOS}

Agradecemos el apoyo de la Mtra. Ana Celia Román Bahena, profesora de la Especialización en Estomatología del Niño y del Adolescente, FES Zaragoza, UNAM. 
El manuscrito fue revisado y editado en el Programa para la Investigación Bibliográfica Científica sobre Salud (PIBCIS) de la FES Zaragoza, UNAM

\section{RefERENCIAS}

1. Sedano H, Moreira L, Alves R, Braga A. Otodental syndrome: a case report and genetic considerations. Oral Surg Oral Med Oral Pathol Oral Radiol Endod. 2001; 92 (3): 12-17.

2. Bloch-Zupan A, Sedano HO, Scully C. Anormalidades de la forma y el tamaño de los dientes. Dento Oro Cran Anom Gen. 2012: 87-99. https:// doi.org/10.1016/b978-0-12-416038-5.00004-4

3. Chen RJ, Chen HS, Lin LM, Lin CC, Jorgenson RJ. Otodental dysplasia. Oral Surg Oral Med Oral Pathol. 1988; 66 (3): 353-358. doi: 10.1016/0030-4220(88)90245-9.

4. Gregory-Evans CY, Moosajee M, Hodges MD, Mackay DS, Game L, Vargesson N et al. SNP genome scanning localizes oto-dental syndrome to chromosome $11 \mathrm{q} 13$ and microdeletions at this locus implicate FGF3 in dental and inner-ear disease and FADD in ocular coloboma. Hum Mol Genet. 2007; 16(20):2482-2493. doi: 10.1093/hmg/ddm204.

5. Kim YS, Kim GH, Byeon JH, Eun SH, Eun BL. Chromosome 11q13 deletion syndrome. Korean J Pediatr. 2016; 59(Suppl 1): S10-S13. doi: 10.3345/kjp.2016.59.11.S10.

6. Orphanet: una base de datos en línea de enfermedades raras y medicamentos huérfanos. Copyright, INSERM 1999. Disponible en http:// www.orpha.net.

7. O'Neill MJ. Displasia otodental [Internet]. OMIM $®$ Online Mendelian Inheritance in Man® An Online Catalog of Human Genes and Genetic Disorders Updated. 2020. Disponible en: https:// www.omim.org/entry/166750? search $=166750 \&$ highlight $=166750 \#$
8. Gómez B, Mendoza A, Solano A, González O. Globodoncia: a propósito de un caso. Odontol Pediátr. 2004; 12 (3): 127-130.

9. Gorlin R. Otodental syndrome, oculo-faciocardiodental (OFCD) syndrome, and lobodontia: dental disorders of interest to the pediatric radiologist. Pediatr Radiol. 1998; 28: 802-804.

10. Torun D, Güran S, Karahatay S, Öncel Z, Gerek M, Bahçe M. A case with neurosensorial hearing loss and anodonty findings: Is this a variant of otodental syndrome?. Turkiye Klinikleri J Med Sci. 2010; 30 (1): 387-391.

11. Manpreet K, Sumati B, Girish KL. Otodental Syndrome. A review of literature. Indian J Stomatol. 2010;1(2): 81-83.

12. Su J, Zeng S, Ye X, Wu Z, Huang X, Pathak J. Three years of follow-up of otodental syndrome in 3-year-old Chinese boy: a rare case report. BMC Oral Health. 2019; 19 (164). https:// doi.org/10.1186/s12903-019-0860-z

13. Liu A, Wu M, Guo X, Guo H, Zhou Z, Wei $K$ et al.. Clinical, pathological, and genetic evaluations of Chinese patient with otodental syndrome and multiple complex odontoma: case report. Medicine (Baltimore). 2017; 96(5):e6014. doi: 10.1097/MD.0000000000006014.

14. Bloch-Zupan A, Goodman JR. Otodental syndrome. Orphanet J Rare Dis. 2006; 21 (1): 5. doi: 10.1186/1750-1172-1-5.

15. Innis J, Sieving P, McMillan P, Weatherly R. Apparently new syndrome of sensorineural hearing loss, retinal pigment pithelium lesions, and discolored teeth. Am J Med Genet. 1998; 75: 13-17.

16. Van Doorne L, Wackens G, De Maeseneer M, Deron P. Otodental syndrome. A case report. Int J Oral Maxillofac Surg. 1998; 27(2):121-124. doi: 10.1016/s0901-5027(98)80309-3.

17. Giraldo-Zuluaga MC, Martínez-Delgado CM, Cardona-Gómez N, Gutiérrez-Pineda JL, Giraldo-Moncada KA, Jiménez-Ruíz PM. Manejo de 
la salud bucal en discapacitados. Artículo de revisión. CES Odontol. 2017; 30(2): 23-36.

18. Hernández CT, Robles NM, Medina CE, Jiménez SI, Centeno C. Manejo odontológico del paciente con hipoacusia neurosensorial profunda bilateral. Rev Cubana Estomatol. 2017; 54 (3).

19. Rodríguez-Batllori L, Pérez P, Pérez L, Rey E, Rodríguez N, Salgado A, et al. Manejo odontopediátrico del paciente con discapacidad visual. Odontol Pediátr. 2013; 21 (2): 122-130.

20. ColterJ. Sedano H. Otodental syndrome: a gise report. Pediatr Dent. 2005; 27: 482-485.

21. Enright S, Humphrys K, Rea G, James J. Globodontia in the otodental syndrome: a rare defect of tooth morphology occurring with hearing loss in an eight-year-old. Dent Update. 2015; 42: 927-932.

22. Szüts J, Németh Z. Odontomák diagnosztikus és terápiás aspektusai a maxillofaciális sebészetben. Fogorvosi Szemle. 2018; 3 (111); 85-90.
23. Cook RA, Cox JR, Jorgenson RJ. Otodental dysplasia: a five year study. Ear Hear. 1981; 2 (2): 90-4. doi: 10.1097/00003446-19810300000007.

24. Witkop CJ Jr, Gundlach KK, Streed WJ, Sauk JJ Jr. Globodontia in the otodental syndrome. Oral Surg Oral Med Oral Pathol. 1976; 41(4) :472-483. doi: 10.1016/0030-4220(76)90275-9.

25. Silva FB, Sampaio LMM, Carrascosa AC. Avaliação fisioterapêutica dos sistemas mastigatório e respiratório de um portador de Síndrome Otodental: um estudo de caso. Rev Bras Fisioter. 2006; 10(1): 133-136. https://doi. org/10.1590/S1413-35552006000100018.

26. Cehreli SB, Brannon RB, Musselman RJ, Tirali RE, Derbent M. Otodental syndrome: a case presentation in a 6-year old child. Eur J Paediatr Dent. 2014 ; 15 (2 Suppl): 215-217. 